\title{
Timing of flood-water inputs to a lake revealed by transient stable isotope mass balance modelling
}

JANIE MASSE-DUFRESNE ${ }^{1}$, FLORENT BARBECOT ${ }^{2}$, PAUL BAUDRON ${ }^{1,3}$ AND JOHN GIBSON ${ }^{4,5}$

${ }^{1}$ Polytechnique Montreal

${ }^{2}$ GEOTOP-UQAM

${ }^{3}$ Institut de Recherche pour le Développement

${ }^{4}$ InnoTech Alberta

${ }^{5}$ University of Victoria

Presenting Author: janie.masse-dufresne@polymtl.ca

Isotope mass balance models have seen significant developments in the last decade for assessing the spatial and temporal variability of hydrological processes in lakes but are generally applied assuming steady-state. While this assumption is generally acceptable for long-term water balances of large lakes, it may be less appropriate for lakes which undergo strong seasonality of hydrological processes and meteorological conditions. In this study, a volume-dependent transient isotopic mass balance model was developed for an artificial lake in Canada, and in a context where direct measurement of surface water fluxes is impossible due to flooding. The isotopic mass balance model revealed that the lake was mainly dependent on groundwater fluxes on an annual timescale, but that flood-water inputs dominated the water balance during the flood event. Additionally, it was shown that bank storage likely contributed flood-water inputs to the lake during summertime, impacting the temporal evolution of the surface water-groundwater apportionment. Using the mean flushing time (i.e., ratio of lake volume to the renewal rate) and the G-index (i.e., ratio of groundwater to total inputs) as bulk parameters of the lakes' resilience, it was demonstrated that accounting for bank storage is crucial to correctly represent their sensitivity to groundwater changes. These findings can help to anticipating the impacts of variation in the intensity and/or duration of future flooding events on lakes' water quality. From a global perspective, this knowledge is useful for establishing regional-scale management strategies for maintaining water quality at flood-affected lakes in a context of land-use and climate changes. 